\title{
Spatial Analysis of Risks and Vulnerabilities to Major Hazards in Madagascar Using the Multi-Criteria Method Based on the Analytical Hierarchy Process (AHP)
}

\author{
Tsiorinantenaina René Rakotoarison'1,2,3, Aimé Richard Hajalalaina1,2,3, \\ Andrianianja Raonivelo ${ }^{4}$, Angelo Raherinirina ${ }^{2,3,5}$, Reziky Tantely Zojaona ${ }^{6}$
}

${ }^{1}$ School of Management and Technological Innovation, University of Fianarantsoa, Fianarantsoa, Madagascar ${ }^{2}$ Laboratory of Computer Science and Mathematics Applied to Development, University of Fianarantsoa, Fianarantsoa, Madagascar ${ }^{3}$ Computer Science, Geomatics, Mathematics and Applications, Hosting Team Fianarantsoa, Fianarantsoa, Madagascar

${ }^{4}$ National Office of Risk and Disaster Management, Antananarivo, Madagascar

${ }^{5}$ National Higher School, University of Fianarantsoa, Fianarantsoa, Madagascar

${ }^{6}$ Polytechnic Superior School of Antananarivo, University of Antananarivo, Antananarivo, Madagascar

Email: rtsiorinantenaina@gmail.com

How to cite this paper: Rakotoarison, $T$. R., Hajalalaina, A. R., Raonivelo, A., Raherinirina, A., \& Zojaona, R. T. (2021). Spatial Analysis of Risks and Vulnerabilities to Major Hazards in Madagascar Using the Multi-Criteria Method Based on the Analytical Hierarchy Process (AHP). Journal of Geoscience and Environment Protection, 9, 15-24.

https://doi.org/10.4236/gep.2021.95003

Received: March 25, 2021

Accepted: May 18, 2021

Published: May 21, 2021

Copyright $\odot 2021$ by author(s) and Scientific Research Publishing Inc. This work is licensed under the Creative Commons Attribution International License (CC BY 4.0).

http://creativecommons.org/licenses/by/4.0/

\begin{abstract}
Natural disasters are not negligible factors that have significant impacts on a country's development. Madagascar cannot escape cyclones, floods and drought due to its geographical situation. The objective in this work is to assess the risks and vulnerability to these hazards in order to strengthen the resilience of the Malagasy population. Our approach is based on multi-criteria spatial analysis using the Analytical Hierarchy Process (AHP). The results form decision spatial information that can be used at the strategic level of natural risk and disaster management. This work focuses on the degree of vulnerability and it was found in this study that the Androy and Atsimo-Atsinanana regions are the most vulnerable to major hazards in Madagascar not only because of their exposure to risk but also because of their very low socio-economic status.
\end{abstract}

\section{Keywords}

Spatial Analysis, AHP, Hazard Risk, Vulnerability, Madagascar

\section{Introduction}

Natural disasters hamper development programs and thus cause the loss of peoples' property which leads to lower economic level (Rafidinarivo et al., 2017). 
Each year, Madagascar is often exposed to the risks of major natural hazards (cyclone, flood and drought). This is due to its geographical and climatic location. The country is affected by cyclones and intense rains which lead to the flooding of lowlands and the rise of rivers. The cyclone season is from November to April from where the cyclones that form in January to March are observed more powerful (Tadross et al., 2008). With the passage of cyclone Giovanna in February 2012, the damage recorded was 35 deaths, 284 injuries, 246,869 victims, 34,182 displaced persons, 44,159 destroyed huts, 27,656 damaged huts and 1135 flooded huts (BNGRC, assessment as of March 28, 2012).

The lack of rainfall in the southern part of Madagascar causes periodic droughts that re-duce the harvests of the main food products (cassava, corn and rice) and lead to food in-security. In addition, the Grand Sud is recorded at a very high level of poverty. In 2009 the number of people requiring immediate emergency intervention reached 191,000 out of 500,000 food insecure, and 200,000 out of 720,000 in 2011 (BNGRC, contingency plan for the Grand Sud 2013-2015).

In this article, the question arises on the assessment of risks and vulnerabilities to major climatic hazards in Madagascar. A multi-criteria spatial analysis approach, based on the Analytical Hierarchy Process, of risks and vulnerabilities to major climatic hazards in Madagascar is proposed. In this analysis, climatological spatial data presented by the reanalysis of the European forecasting center ECMWF and socio-economic spatial data obtained by the MDGs (Millennium Development Goals) surveys are used. The results constitute elements of reflection and decision-making in the field of risk management and natural disasters.

\section{Material and Methods}

Madagascar's rainfall varies according to the regions, the eastern part is the most watered while in the southern part, and the rainfall deficit affects the regions and leads to drought. The great south of the country is an arid zone which receives on average only $500 \mathrm{~mm}$ of rain per year. Annual precipitation does not even reach $300 \mathrm{~mm}$ during the period of acute drought. Author name, affiliation and complete address are to be placed underneath the title. In case of multiple authorship of a submitted paper, the affiliation and complete address of each author must be specified (BNGRC, 2011-2012). Madagascar is affected by cyclones almost every year. Heavy rains and extreme winds cause direct mortality, flooding, damage to infrastructure such as roads, schools, health centers and people's homes as well as crop destruction and landslides (CPGU, BNGRC, PNUD, 2014) Madagascar is the 1st in Africa most vulnerable to climatic hazards and the 3rd country in the world after Bangladesh and India (Macary et al., 2010). The east coast is the most exposed by the tropical cyclone that forms in the Indian Ocean.

Madagascar is classified as a poor and least developed country, according to the World Bank. The country regressed from its 2010 ranking of 135th to 151st in 2012 according to the Human Development Report. 71.5\% of the population 
is classified as poor in 2013 according to the national threshold of 535,603 Ar per person, per year, of which $52.7 \%$ live in extreme poverty. The 9 regions out of the 22 regions of Madagascar have a poverty rate of less than $80 \%$, the Androy region is the most affected as almost all its population (97\%) lives in poverty. Five other regions have poverty rates between 70 and less than $80 \%$ of their population (Foerster, 2009). The Human Development Index (HDI) is 0.4982 which classifies the country in the group of countries with low human development by the threshold of 0.5 and that Madagascar is placed 155th out of 187 countries.

Vulnerability is the trend in a community's situation that can be damaged by the negative effects of hazards and which varies according to the community, in time and also in space (Rousseau, 2007). For the analysis of vulnerability, it is necessary to identify the exposure to climate risk of the issues at stake but also their socio-economic vulnerability which is determined the capability approach by Sen Amartya (Wells, 2012). Vulnerability is thus determined by the direct relationship between risk and capability (Rousseau, 2003).

$$
\text { vulnerability }=\text { risk/capability }
$$

Multi-criteria analysis is a mathematical method to help decision-makers when faced with a complex problem that depends on several criteria of a qualitative or quantitative nature (Navalho et al., 2019). Several multi-criteria analysis models are developed that are differentiated by their aggregation processes. Spatially referenced decision problems are multi-criteria in nature (Chakhar \& Martel, 2004). Several works on the integration of multi-criteria spatial analysis have been published since 1990. In 2010, Macary et al. (2010) used a multi-criteria spatial analysis approach with the ELECTRE Tri method for decision support in the field of agricultural and environmental risk management in the local context in Normandy, France, in the Oir catchment area. This study shows the efficiency of the method used but the computerized implementation of spatial processing with this method still remains a prospect. Navalho et al. (2019) carry out a comparative analysis of the current distribution of forest areas with multi-criteria spatial analysis using the analytical hierarchy process (AHP) integrating three factors (slope of the terrain, soil diagnostic characteristics and bioclimatic indices). The problem with spatial analysis is that the data are complex, heterogeneous and non-linear because the existing and geographical phenomena are characterized by their position, shape, descriptive attributes, topological relationships and formats according to their source (Chakhar, 2006). The area to be analyzed is continuous or the number of possibilities is very high, e.g. all the pixels of the map. Therefore, with certain methods, the computation time becomes very important. The Analytic Hierarchy Process by (Saaty 1980) and the weighted sum method have been proposed because of its simplicity, which makes it easy to explain it to a decision-maker, but also because it is quick to use. It is one of the easiest methods to implement by scripts because the operations are not complex with more or less reduced calculation time compared to other methods. Analytical Hierarchy Process allows to decompose the complex prob- 
lem into a hierarchical structure (levels). The problem is broken down into three levels to assess vulnerability to major risks in Madagascar, shown in Figure 1 and Table 1.

A weighted linear combination is applied to the different level 3 and level 2 factors of the analysis hierarchy (Deepak et al., 2020) according to the equation:

$$
S=\sum w_{i} \cdot x_{i}
$$

Hence $x_{i}$ : value of normalized factors

$W_{i}$ : estimated weight of each factor

$S$ : score or linear combination of factor values $\left(x_{i}\right)$ weighted by weights $\left(w_{i}\right)$

The different factors are rarely expressed in the same unit. To be able to combine factors, it is necessary to normalize them using reduced centered variables.

$$
x_{i}=\frac{f_{i}-\bar{f}}{\sigma_{f}}
$$

Hence $f_{i:}$ factor values

$\bar{f}$ : Average of factors

$\sigma_{f}$ Standard deviation

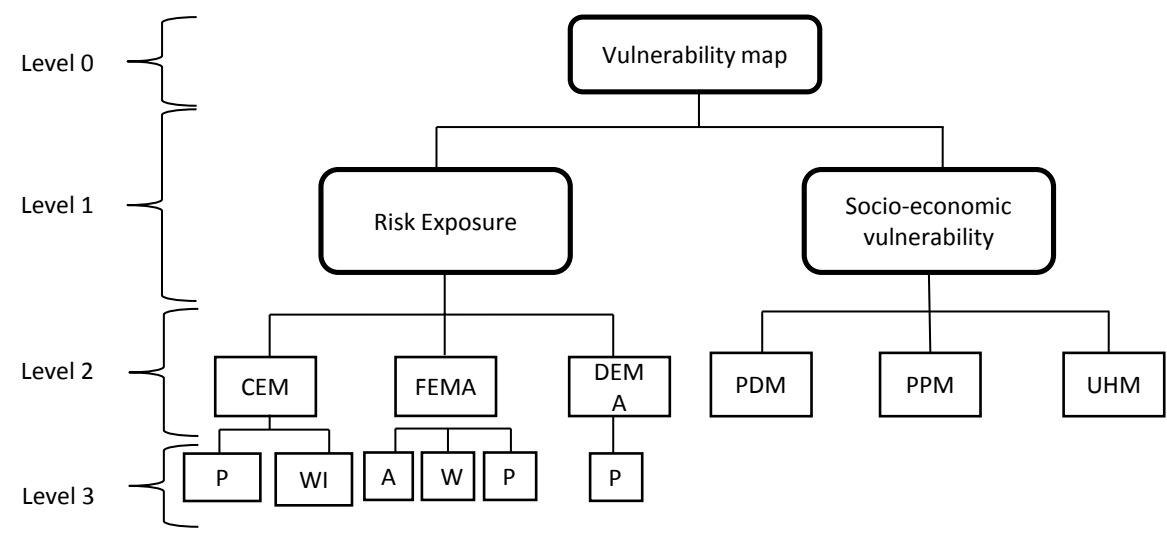

Figure 1. Hierarchical structure for the analysis of vulnerability to cyclones, floods and drought hazards.

Table 1. Legend of Figure 1.

\begin{tabular}{cc}
\hline Abbreviation & Meaning \\
\hline CEM & Cyclone exposure map \\
FEM & Flood exposure map \\
DEM & Drought exposure map \\
PDM & Population density map \\
PPM & Population poverty map \\
UHM & Unsustainable housing map \\
P & Precipitation \\
WI & Wind intensity \\
A & Altitude \\
W & Watershed \\
&
\end{tabular}


At level 1 of the analysis hierarchy, the relationship between climate risk and socio-economic vulnerability presented by Equation (1) is applied. A linear stretch between the maximum and minimum values of the result is performed to have a gradation of the degree of vulnerability between the values of 0 and 1 according to equation:

$$
v=\frac{R_{i}-R_{\min }}{R_{\max }-R_{\min }}
$$

Hence $R_{i}$ : result values

$R_{\min }$ : minimum value of the result

$R_{\text {max }}$ : maximum value of the result

For the data, ECMWF (European Center for Medium-Range WeatherForecasts) reanalysis data for climate variables, the IBTrACS (International Best Track Archive for Climate Stewardship) database (Knapp, 2010) for information on cyclones and tropical storms and the MDG (Millennium Development Goals) report for socio-economic (INSTAT, 2012-2013) variables are used.

\section{Results and Discussions}

\subsection{Results of Risk Exposure Analysis of Major Hazards in Madagascar}

The risk exposure maps for the main hazards (cyclone, flood, and drought) in Madagascar are shown in Figure 2. The northeast part and the east coast are the most affected by cyclones. Cyclones that form in the East in the Indian Ocean are the most frequent in Madagascar. It reaches $68 \%$ of the cyclones that passed through Madagascar since the 1998 to 2015 cyclone season. Madagascar's eastern coasts are still at risk of flooding. Similarly, parts of the west coast of the country are also at risk with a higher degree of exposure in the regions of Melaky, Boeny, Menabe and Atsimo Andrefana. The analysis also detected that the southwestern and southern part of Madagascar are dry areas. The Antsimo-andrefana region has a very high degree of exposure to drought risks.

After weighting the degrees of exposure to the risks of cyclone, drought and flood hazards, the risk map for the main hazards is shown in Figure 3. The region of Antsimo-Andrefana is the highest risk because it is almost affected by these three hazards. After Antsimo-Andrefana, the Sava region also has high values due to its exposure to the risks of cyclones and floods. The eastern part is an entry point for cyclones that form in the Indian Ocean and is the most frequent in Madagascar.

\subsection{Results of Socio-Economic Factors}

The study considers three socio-economic factors to assess the vulnerability of issues to major risks (cyclone, flood and drought) such as population density, poverty and type of housing. The population density shows the inequality of distribution of the inhabitants. It is true that the Analamanga region has a high 


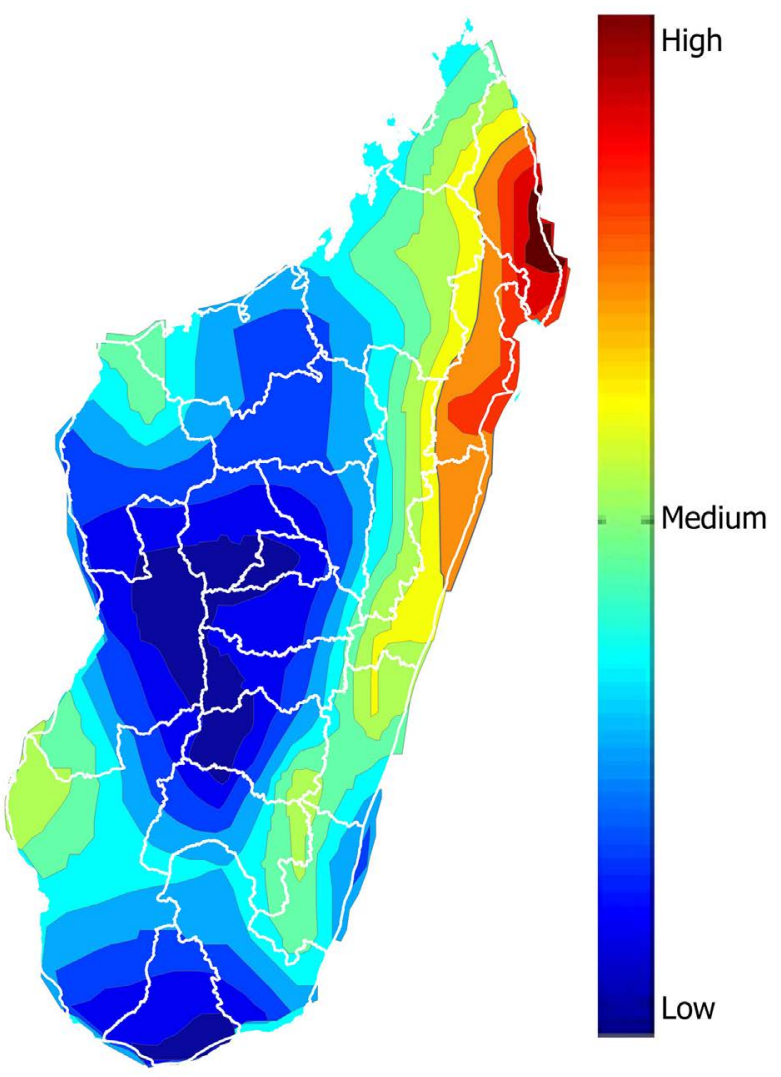

(a)

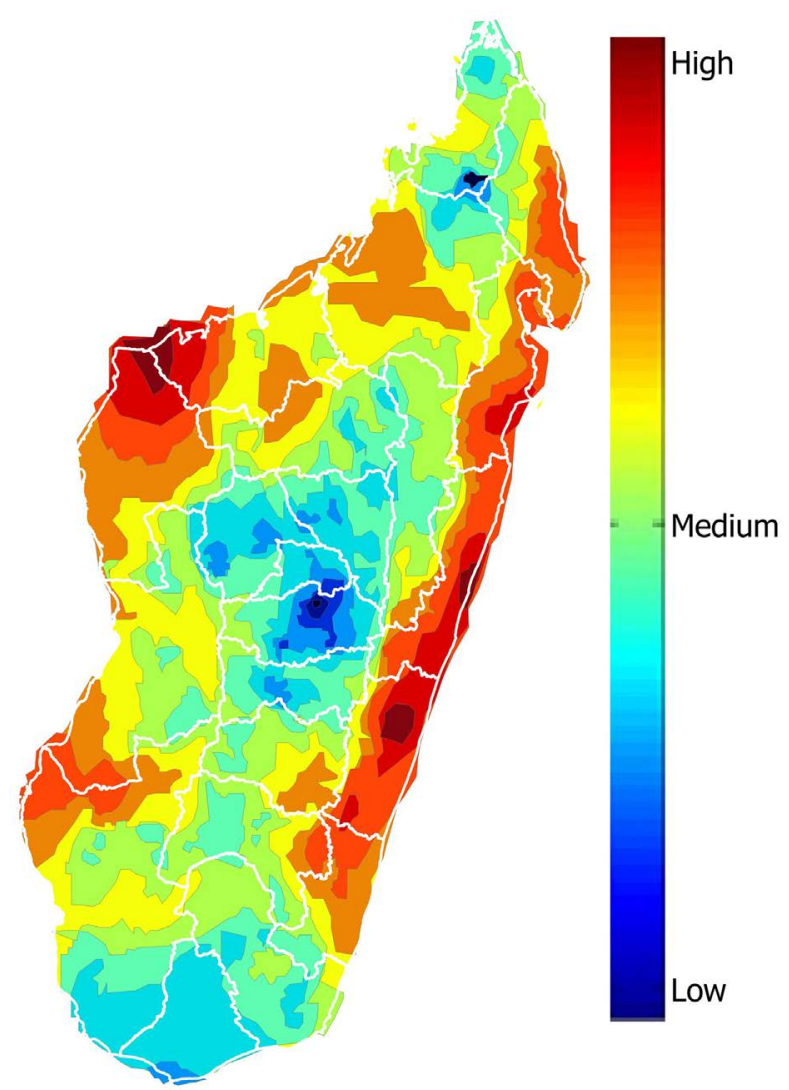

(b) 


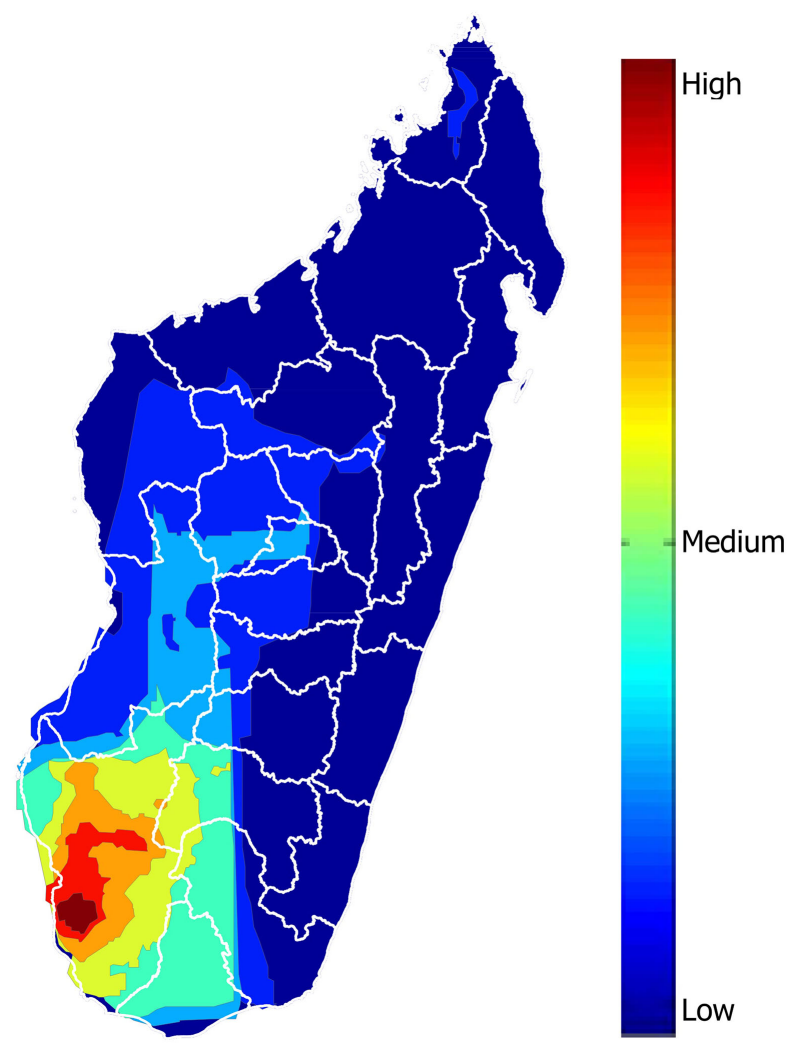

(c)

Figure 2. Exposure to the risks of cyclones (a), floods (b) and droughts (c).

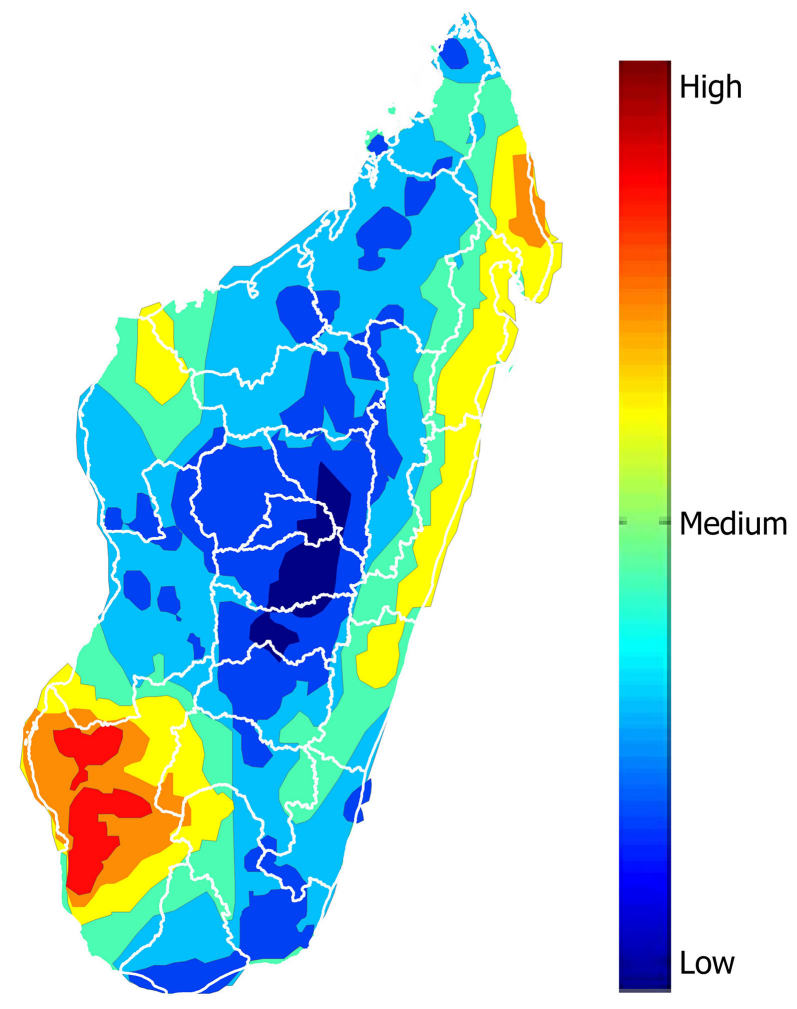

Figure 3. Risk to major hazards. 
population density, as more than $13 \%$ of the total population is located in this region. However, it has a lower rate of poverty than the others and sustainable types of housing. Therefore, the Analamanga region is classified as non-vulnerable. Poverty is an amplifying factor of vulnerability, as it measures the capacity of an individual or household to respond to the disaster. The Androy region is the most affected, as almost its entire population (97\%) lives in poverty. The regions of Vatovavy-fitovinany and Atsimo-Atsinana are also very vulnerable, not only because of poverty, but also because of the type of dwellings built with vegetal materials that are fragile to cyclones and floods. Figure 4 illustrates this.

\subsection{Vulnerability Assessment}

Applying the direct relationship between major hazard risk and socio-economic status to Equation (1), the result is a map of vulnerability to major hazards in Madagascar (cf Figure 5). The Androy and Atsimo-Atsinanana regions are very vulnerable due to their intense poverty and unsustainable housing type. Being an entry point for cyclones that form in the Indian Ocean, the SAVA region also has a high degree of vulnerability. The Diana and Analamanga regions have a considerable capacity to adapt to disasters due to their high living standards and low poverty rate. These two regions are the most resilient of all regions in Madagascar.

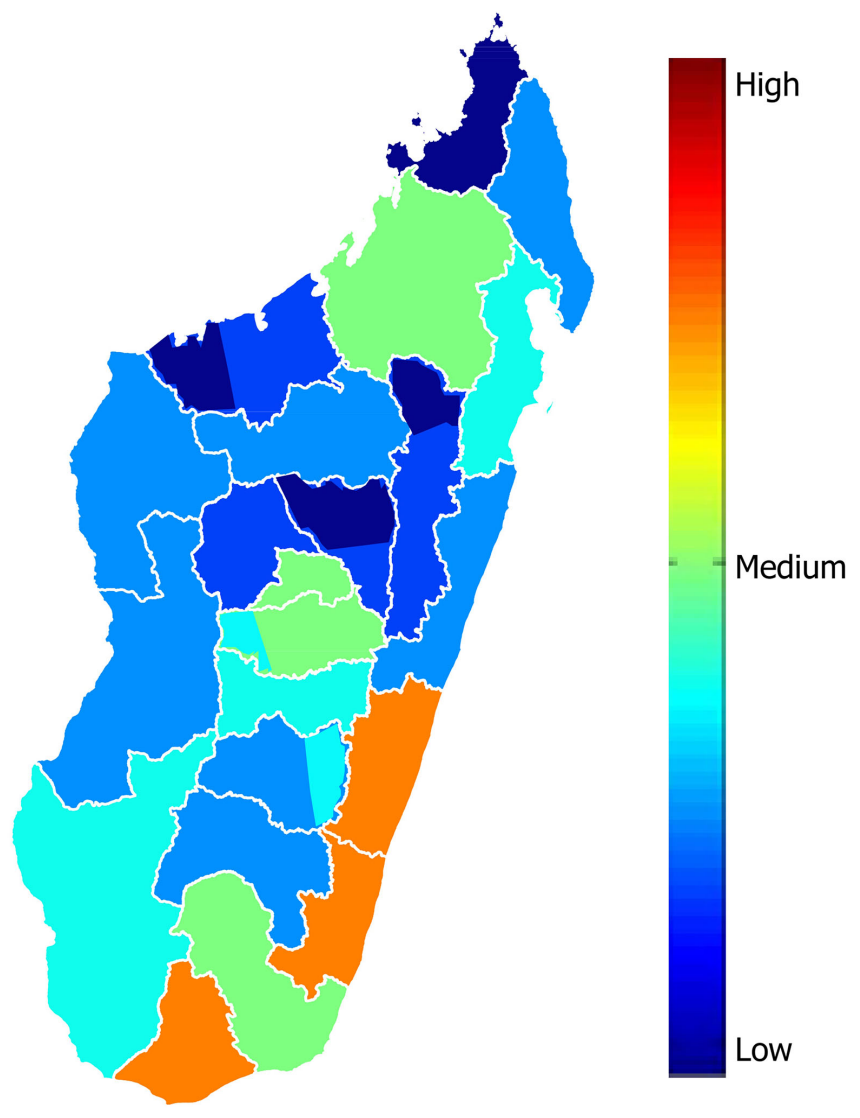

Figure 4. Socio-economic vulnerability. 


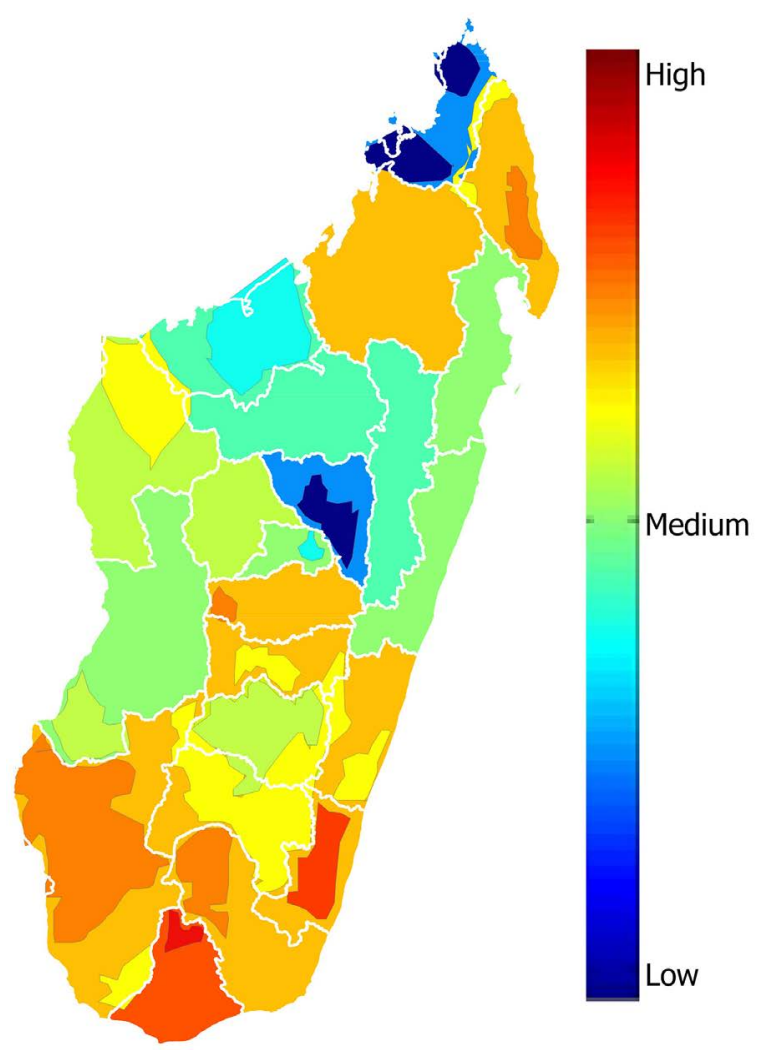

Figure 5. Vulnerability map to major hazards.

\section{Conclusion}

Our work consists of the spatial analysis of vulnerability to major hazards, namely cyclone, flood, drought, in Madagascar by considering climatic and physical factors as well as socio-economic factors. The multi-criteria approach based on the analytical hierarchy process was used. It breaks down the problem into several levels depending on the factors considered to make the analysis step understandable. The resulting map shows a wide variation in vulnerability levels in Madagascar. The results provide food for thought and decision-making support for risk reduction, capacity building of populations and the choice of infrastructure resistant to the hazards that frequently occur. The weights assigned to each climatic and especially socio-economic variable are still a debatable subject to improve the precision of the results. The proposal for a formalized processing chain is a perspective for the automation, reuse and sharing of this experience.

\section{Conflicts of Interest}

The authors declare no conflicts of interest regarding the publication of this paper.

\section{References}

BNGRC (2011-2012). Plan national de contingence Cyclones et inondations.

Chakhar, S. (2006). Cartographie décisionnelle multicritère: formalisation et implémenta- 
tion informatique. Université Paris Dauphine-Paris IX.

Chakhar, S., \& Martel, J. M. (2004). Towards a Spatial Decision Support System: Multi-Criteria Evaluation Functions inside Geographical Information Systems. Annales du LAMSADE, 2, 97-123.

CPGU, BNGRC, PNUD (2014). Stratégie nationale de Gestion des Risques et Catastrophes 2016-2020. Antananarivo.

Deepak, S., Rajan, G., \& Jairaj, P. G. (2020). Geospatial Approach for Assessment of Vulnerability to Flood in Local Self Governments. Geoenvironmental Disasters, 7, Article No. 35. https://doi.org/10.1186/s40677-020-00172-w

Foerster, E. (2009). Vulnérabilité: État de l'art sur les concepts et méthodologies d'évaluation. RP-57471-FR, 32 p.

INSTAT (2012-2013). Enquête nationale sur le suivi des objectifs du millénaire pour le développement à Madagascar. Résumé des rapports sur l'ENSOMD.

Knapp, K. R., Kruk, M. C., Levinson, D. H., Diamond, H. J., \& Neumann, C. J. (2010). The International Best Track Archive for Climate Stewardship (IBTrACS) Unifying Tropical Cyclone Data. Bulletin of the American Meteorological Society, 91, 363-376. https://doi.org/10.1175/2009BAMS2755.1

Macary, F., Ombredane, D., \& Uny, D. (2010). A Multicriteria Spatial Analysis of Erosion Risk into Small Watersheds in the LOW NORMANDY BOCAGE (France) by ELECTRE III Method Coupled with a GIS. International Journal of Multicriteria Decision Making, 1, 25-48. https://doi.org/10.1504/IJMCDM.2010.033685

Navalho, I., Alegria, C., Roque, N., \& Quinta-Nova, L. (2019). Mapping Forest Landscape Multifunctionality Using Multicriteria Spatial Analysis. Floresta e Ambiente, 26, e20170702. https://doi.org/10.1590/2179-8087.070217

Rafidinarivo, H. C., Ralamboson, H., \& Ranaivoarivelo, M. D. (2017, February). Transition politique et transition humanitaire: Analyse politique comparée de la transition financière. In «La «localisation» de l'aide internationale, discours et réalités du transfert de l'action humanitaire du global au local», Transition humanitaire: Les états de la recherche, Fonds Croix-Rouge Française.

Rousseau, S. (2003). Capabilités, risques et vulnérabilité. Pauvreté et Développement Socialement Durable, 11-22.

Rousseau, S. (2007). Vulnérabilité et résilience, analyse des entrées et sorties de la pauvreté: Le cas de Manjakandriana à Madagascar. Mondes en Développement, 4, 25-44. https://doi.org/10.3917/med.140.0025

Saaty, T. L. (1980). The Analytical Hierarchy Process, Planning, Priority, Resource Allocation. USA: RWS Publications.

Tadross, M., Randriamarolaza, L., Rabefitia, Z., \& Zheng, K. Y. (2008). Climate Change in Madagascar; Recent Past and Future (p. 18). Washington DC: World Bank.

Wells, T. R. (2012). Sen’s Capability Approach. 